\title{
O enunciador em um conto de Clarice Lispector
}

\author{
El enunciador en un cuento de Clarice Lispector
}

\section{The enunciator in a short story by Clarice Lispector}

\author{
Ernani Terra*
}

\begin{abstract}
RESUMO: Objetiva-se mostrar como um enunciador falante do português brasileiro produz um discurso em que se apresenta como falante nativo do português europeu. Pretende-se responder às seguintes perguntas: a) Por que uma autora falante da variedade brasileira escreve um conto na variedade europeia do português? b) Quais os efeitos de sentido produzidos pelo uso dessa variedade? A fundamentação teórica recai na Semiótica discursiva e na teoria da enunciação. A metodologia consiste na análise do conto Devaneio e embriaguez duma rapariga, de Clarice Lispector, a partir das escolhas lexicais e sintáticas do enunciador manifestadas no plano da expressão. Discursos em que falantes do português brasileiro procuram reproduzir a variedade europeia do português costumam se valer de procedimentos estereotipados: na linguagem oral, centram-se na tentativa de reproduzir os aspectos prosódicos; na escrita, recaem principalmente na utilização de um léxico que atesta as diferenças entre as duas variedades. Os resultados da análise mostram que o enunciador, para passar a imagem ao enunciatário de um falante nativo do português europeu, não se restringiu somente a aspectos linguísticos, mas também a aspectos discursivos, especialmente aqueles relativos à projeção das categorias da enunciação no nível discursivo.
\end{abstract}

PALAVRAS-CHAVE: Variedade linguística. Semiótica. Enunciação. Literatura.

RESUMEN: Se objetiva enseñar, cómo un enunciador, hablante de portugués brasileño, produce un discurso en el que se presenta como un hablante nativo del portugués europeo. Se pretende responder a las siguientes preguntas: a) ¿Por qué una autora hablante de la variedad brasileña escribe un cuento en la variedad europea del portugués? b) ¿Cuáles son los efectos de sentidos producidos por el uso de esa variedad? Los fundamentos teóricos están basados en la semiótica discursiva y en la teoría de la enunciación. La metodología consiste en el análisis del cuento Devaneio e embriaguez duma rapariga, de Clarice Lispector. Discursos en los que los hablantes de portugués brasileño buscan reproducir la variedad europea de portugués suelen recurrir a procedimientos estereotipados: en el lenguaje oral se concentran en el intento de reproducir aspectos prosódicos; en la escritura, inciden principalmente en el uso de un

\footnotetext{
* Doutor em Língua portuguesa pela PUC-SP e pós-doutorado na Universidade Presbiteriana Mackenzie (UPM). Membro do Grupo de Estudos Semióticos da Universidade de São Paulo (GES-USP) de GT de Semiótica da Anpoll. E-mail para contato: ernani@uol.com.br
} 
léxico que demuestra las diferencias entre las dos variedades. Los resultados del análisis señalan que, para convertir la imagen de un hablante nativo de portugués europeo ante el enunciatario, el enunciador no se limita solamente a los aspectos lingüísticos, sino también a los aspectos discursivos, especialmente aquellos relativos a la proyección de las categorías de la enunciación a nivel discursivo.

PALABRAS CLAVE: Variedad lingüística. Semiótica. Enunciación. Literatura

\begin{abstract}
This article aims to demonstrate how a enunciator, native speaker of Brazilian Portuguese, creates a discourse on what show itself as a native speaker of European Portuguese. Intends to answer the following questions: a) Why a writer speaker of the Brazilian Portuguese writes a short story that uses the European Portuguese? b) Which are the effects in terms of sense produced by the use of this variety? The theory foundation relies on the Discursive Semiotics and in the theory of the enunciation. The methodologic consists in the analysis of the short story Devaneio e embriaguez duma rapariga, by Clarice Lispector, from the lexical and synthetic choices of the enunciator expressed in the plan of expression. Discourses in which Brazilian Portuguese speakers seek to reproduce the European Portuguese variety usually makes use of stereotyped procedures: in the oral language focus on the attempt to reproduced the prosodic aspects; in the written, relies mostly in the use of a lexicon that attests the differences between the two varieties. The analysis results show that the enunciator, to draw for the enunciate the image of a native speaker of the European Portuguese, did not limit itself to linguistic aspects, but also to discursive aspects, especially those related to the projection of the categories from enunciation in the discursive level.
\end{abstract}

Keywords: Linguistic variety. Semiotic. Enunciation. Literature.

\title{
Considerações Iniciais
}

Pretende-se mostrar, a partir de uma análise do conto Devaneio $e$ embriaguez duma rapariga, de Clarice Lispector, reproduzido na íntegra no anexo deste artigo, que a diversidade entre duas variedades linguísticas do português, a europeia e a brasileira, está além do enunciado, podendo ser apreendida também na instância da enunciação, vale dizer, a maneira pela qual os falantes do lado de cá e os do lado de lá do Atlântico se apropriam da língua para convertê-la em discurso é diferente. Essa tese encontra guarida em Mira Mateus e outras (1989) e Orlandi (2002). As primeiras, referindo-se às diferenças entre o português europeu e o brasileiro, afirmam que "dadas as características morfológicas e sintáticas das diferentes línguas, podemos admitir que categorias básicas como o Tempo e o Espaço apresentam modos distintos de representação, 
quer a nível cognitivo, quer a nível de verbalização" (MIRA MATEUS et al., 1989, p. 27). A segunda ressalta que "no caso do português, podemos dizer, então, que são distintos sistemas simbólicos (o do Brasil e o de Portugal) com distintas histórias (linguísticas), mas apresentando a mesma materialidade empírica" (ORLANDI, 2002, p. 24). Se as categorias de tempo e de espaço têm representações diversas a nível cognitivo, a diferença entre as duas variedades do português, o europeu e o brasileiro, está aquém da materialidade linguística, embora só por ela possa ser identificada uma vez que a enunciação é sempre pressuposta pelo enunciado.

De fato, a diversidade que marca o português brasileiro é endógena, ou seja, tem sua referência na cultura brasileira cujo sistema de representação difere do de Portugal. O conceito de nação envolve a questão da identidade, que passa por reconhecer que a língua nacional é diferente. Nações diferentes que são, Portugal e Brasil têm línguas diferentes. Antes, porém, algumas palavras a respeito do conto.

\section{o Conto - Objeto da Análise}

Devaneio e embriaguez duma rapariga é o primeiro conto de Laços de família, cuja primeira edição foi publicada em 1960 pela Editora Rocco. Ressaltase que vários contos do livro já haviam sido publicados em 1952 pelo Ministério da Educação e Saúde, num livro denominado Alguns contos.

A temática de Laços de familia, como se depreende do título, são as relações familiares. Dos treze contos do livro, dez tratam da condição feminina na família. As personagens são mulheres que encarnam os papéis temáticos de mãe, de esposa e de dona de casa que, em decorrência de um acontecimento fortuito, veem-se fora de si mesmas. Escolheu-se esse conto devido a seu caráter original dentro da produção literária brasileira, não pelo fato de apresentar uma personagem de nacionalidade portuguesa falando o português europeu, mas principalmente por apresentar um narrador heterodiegético que se manifesta na variedade europeia do português, vale dizer, se não houvesse no paratexto a 
identificação do autor empírico, o leitor seria levado a crer que se trata de uma produção de autor lusitano.

As linhas iniciais do conto já provocam um estranhamento no leitor, sobretudo naquele que conhece a obra de Lispector. O estranhamento será ainda maior se fizer a leitura do livro na ordem em que os contos aparecem, pois Devaneio e embriaguez duma rapariga é, como se afirmou, o conto que abre o livro. O leitor pode ser levado a pensar que tem à mão o livro de um autor português ou que, conhecendo a autora, pensar que se adaptou o texto de Clarice Lispector à variedade europeia da língua portuguesa. O conto se inicia pela voz de um narrador heterodiegético.

Pelo quarto parecia-lhe estarem a se cruzar os elétricos, a estremecerem-lhe a imagem refletida. Estava a se pentear vagarosamente diante da penteadeira de três espelhos, os braços brancos e fortes arrepiavam-se à frescurazita da tarde. Os olhos não se abandonavam, os espelhos vibravam ora escuros, ora luminosos. Cá fora, duma janela mais alta, caiu à rua uma cousa pesada e fofa. Se os miúdos e o marido estivessem à casa, já Ihe viria à ideia que seria descuido deles. Os olhos não se despregavam da imagem, o pente trabalhava meditativo, o roupão aberto deixava aparecerem nos espelhos os seios entrecortados de várias raparigas (LISPECTOR, 2016b, p. 135).

A ficcionalidade do conto vai além do enunciado estendendo-se à enunciação. A autora, uma falante nativa da variedade brasileira do português, afirma que se divertiu muito escrevendo-o, como se observa no depoimento que segue.

De Devaneio e embriaguez duma rapariga sei que me diverti tanto que foi mesmo um prazer escrever. Enquanto durou o trabalho, estava sempre de um bom humor diferente do diário e, apesar de os outros não chegarem a notar, eu falava à moda portuguesa, fazendo, ao que me parece, experiência de linguagem. Foi ótimo escrever sobre a portuguesa (LISPECTOR, 2016a, p. 644).

A experiência de linguagem a que se refere Clarice consiste em se valer de recursos lexicais, morfológicos, sintáticos e fonológicos que caracterizam a variedade europeia do português. 
Quadro 1 - Recursos lexicais, morfológicos e sintáticos

\begin{tabular}{|l|l|l|}
\hline lexical & morfológico & sintático \\
\hline elétricos & frescurazita & parecia-lhe estarem \\
\hline miúdos & vestidito & caiu à rua \\
\hline raparigas & maldadezita & Estava a se pentear \\
\hline palestra / palestrar & santazitas & estivessem à casa \\
\hline quinta & santarrona & veio procurar-me cá à casa \\
\hline pequeno almoço & cinturita & se mo permite \\
\hline fato & fidalguita & ficou-se à cama \\
\hline não me maces & friozito & ainda à cama \\
\hline casa de banhos & deditos & se Ihe tinham vindo febres \\
\hline peúgas & gorditos & Ai que cousa que se me dá \\
\hline tasca & desgraçadinhos & \\
\hline parola & pouquito & \\
\hline borrachona / borracho & coitadita & \\
\hline criado de mesa & chatura & \\
\hline pasto & sujidades & \\
\hline fato & fidalguita & \\
\hline maçada / maçar & & \\
\hline mafarrico & & \\
\hline
\end{tabular}

Fonte: Elaboração própria

Além disso, no nível fonológico, há a tentativa de reprodução do acento lusitano, marcado ortograficamente pelo uso do apóstrofo para indicar a contração de fonemas vocálicos: "voou pralém do Minho"; "D'impaciência"; "cheio d'enfeites"; "parola d'aldeia"; "cheio d'empenho e d'humildade"; "cheiro d'azeite"; "já d'entradd"; "dos chapéus e d'ornatos"; "vontade d'ir e d'encherIhe"; " vendeira d'hortaliça"; "pensas que t'invejo".

Ressalte-se ainda que outras vozes se manifestam no discurso por meio de ditados próprios da cultura lusitana como "Quem viu o pardalzito... passou pela janela... voou pr'além do Minho"; "quem encontrou, buscou"; "subir a mostarda ao nariz". 
O uso de determinadas figuras como segundo elemento de comparações também remete a um enunciador lusitano: "loira como um escudo falso"2; "o sol preso pelas persianas tremia na parede como uma guitarra".

\section{Perguntas}

As perguntas que se pretendem responder são: a) Por que uma autora falante da variedade brasileira do português escreve um conto na variedade europeia? b) Quais os efeitos de sentido produzidos pelo uso dessa variedade?

Quanto ao ator do enunciado, as enunciações na variedade lusitana conferem efeito de verossimilhança ao narrado, expressas em discurso direto, teatralizam a fala da rapariga, produzindo efeitos de sentido de realidade. Sendo lusitana, não há para o enunciatário qualquer estranhamento no fato de suas enunciações serem manifestadas na variedade europeia. Reitera-se a pergunta: por que o enunciador também se vale dessa variedade? Para encontrar a resposta, há de se fazer uma leitura do conto, observando-se o percurso gerativo do sentido, com uma reflexão mais ampla na sintaxe discursiva, particularmente na análise das relações entre ator da enunciação e ator do enunciado, e uma análise do componente figurativo.

\section{Estrutura e paráfrase do conto}

No nível fundamental, o conto se estrutura na oposição semântica /liberdade vs. dominação/ em que liberdade é o valor eufórico e dominação, o disfórico.

2 No texto, escudo refere-se à moeda que circulava em Portugal na época em que o conto foi escrito, posteriormente foi substituída pelo euro. 
Esquema 1 - Oposição semântica fundamental

liberdade dominação

não dominação não liberdade

Fonte: Elaboração própria

Nega-se a dominação para afirmar a liberdade, valor com o qual o sujeito da ação quer entrar em conjunção; para tanto, terá de romper contratos que dizem respeito ao papel da mulher na sociedade e na família. Trata-se de uma narrativa em que há transgressão do papel feminino de submissão aos laços de família. Para o sujeito entrar em conjunção com o objeto de valor, liberdade, há que se abrir uma fenda, destruindo ligações, rompendo contratos.

Um acontecimento banal na vida da rapariga é responsável pela fenda, que a leva ao devaneio. Sozinha em casa, a se pentear, a rapariga vê a imagem de si projetada no espelho.

Estava a se pentear vagarosamente diante da penteadeira de três espelhos [...] Os olhos não se abandonavam, os espelhos vibravam ora escuros, ora luminosos. Os olhos não se despregavam da imagem, o pente trabalhava meditativo, o roupão aberto deixava aparecerem nos espelhos os seios entrecortados de várias raparigas (LISPECTOR, 2016b, p. 135).

O espelho, como se sabe, multiplica a imagem. O eu se desdobra, cria seu duplo. Como no conto $O$ espelho, de Machado de Assis, o sujeito da ação vê sua alma interior projetada no espelho. A rapariga, dona de casa, vê a mulher que ela é. A liberdade, valor buscado, está, pois, em negar a dona de casa e esposa: "[...] o homem lá que se regalasse com as sobras do almoço [...] e nem olhouIhe o fato, se estava ou não por escovar $[. .]$.$" , e afirmar a mulher e isso remete$ ao rompimento com os laços de família (LISPECTOR, 2016b, p. 136). 
Ao ver projetado no espelho seu eu mulher, passa a sonhar acordada (devaneio): "[...] aguardava seu próximo pensamento de olhos abertos" (LISPECTOR, 2016b, p. 136).

Encontrar o eu mulher implica não só negar a dona de casa, mas também a dominação por parte do homem, o casamento como laço de família, tanto que o marido, ao tentar beijar a rapariga, é repelido por ela, para estranheza deste, que fica atônito com a reação da mulher, como se observa nesta passagem em que as vozes dos interlocutores marido e mulher emergem em discurso direto.

- Larga-te daí!

- E o que tens?, pergunta-lhe o homem atônito, a ensaiar imediatamente carinho mais eficaz. [...]

- Ai que não me maces! Não me venhas a rondar como um galo velho! (LISPECTOR, 2016b, p. 136-137).

A figura do galo é significativa não só no conto, como na obra de Clarice. Se no conto, "Uma galinha", também de Laços de família, esse animal é a figura da maternidade (no conto, a galinha fora salva da morte por botar um ovo), em Devaneio e embriaguez duma rapariga, o galo é símbolo do macho dominador, o ditado popular "Onde canta o galo, não canta a galinha" é significativo.

O devaneio, ao romper com o real, com os laços de família, leva a rapariga ao sonho de uma mulher liberta das obrigações domésticas e da sujeição ao macho dominador. Esse eu do devaneio é a mulher liberta dos laços de família, pronta para amar sem culpa como atesta a passagem "Estava previamente a amar o homem que um dia ela ia amar. Quem sabe lá, isso às vezes acontecia, e sem culpas nem danos para nenhum dos dois" (LISPECTOR, 2016b, p. 137).

Em seu devaneio, a rapariga vê assomar à lembrança um acontecimento ocorrido num passado recente. Num sábado, ela e o marido tinham ido a uma tasca da Praça Tiradentes atendendo a um convite de um amigo do marido, homem rico e fino. A rapariga então se embriaga. Os efeitos do vinho fazem misturar aquilo que nela existia separado. 
E quando estava embriagada, como num ajantarado farto de domingo, tudo o que pela própria natureza é separado um do outro - cheiro d'azeite dum lado, homem doutro, terrina de um lado, criado de mesa doutro - unia-se esquisitamente pela própria natureza, e tudo não passava duma sem-vergonhice só, duma só marotagem (LISPECTOR, 2016b, p. 138).

Isso Ihe facilita o rompimento com as convenções, facilitando "um tal desdenho por tudo, a torná-la madura e redonda como uma grande vaca". Eros vence Tanathos, pois se este representa a destruição de ligações, aquele representa a fusão por meio do desejo amoroso.

Num estado de extrema sensibilidade, passa a desprezar as pessoas que vira no restaurante, em especial uma rapariga acompanhada de seu homem, toda enfeitada. A rapariga faz com que sua irritação aumente e sua voz emerge em forma de monólogo interior: "vai ver que nem casada era"; "vai ver que nem era capaz de parir-Ihe, ao seu homem, um filho"; "nem roliça era, era chata de peito"; "não passava duma vendeira d'hortaliça a se fazer passar por grande dama". Sentira-se humilhada pela presença da outra que, ao contrário dela, viera à tasca de chapéu.

O episódio de sua embriaguez na tasca traz-lhe uma tristeza decorrente de um sentimento de culpa, não só por ter se embriagado, mas também por, após o acontecimento, ter se largado e abandonado as obrigações domésticas: "Empanturraste e eu que pague o pato". É dominada pela hybris, culpa trágica que decorre do excesso, da desmedida. Conforma-se com sua condição: "Enfim, ai de mim, seja lá o que Deus bem quiser". Mas, em seu devaneio, retorna ao restaurante e lembra-se que o protetor do marido encostara, por debaixo da mesa, seu pé no dela. Por acaso ou de propósito? Pensa ela. E continua devaneando: o amigo do marido era lá bem interessante. Sente-se triste e culpada. Monologa: "que relaxada e preguiçosa me saíste!"; "a casa havia de ver", iria limpá-la toda "dar-lhe-ia um esfregaço com água e sabão que se arrancariam as sujidades todas". Sente-se resignada. Olhava a lua nessa noite de verão. "Então a grosseria explodiu-Ihe em súbito amor; cadela, disse a rir". 


\section{O devaneio}

Como se pode observar pela paráfrase que se fez do conto, trata-se de uma narrativa feita por um observador de um fato anterior à enunciação (a embriaguez está contida no devaneio e é passada em relação ao momento do devaneio).

Para Bachelard (2009, p. 5) vive-se o devaneio "[...] num tempo de distensão, tempo sem força litigante. Sendo destituído de atenção, não raro é destituído de memória. $\mathrm{O}$ devaneio é uma fuga para fora do real, nem sempre encontrando um mundo irreal consistente."

Para o filósofo francês, apoiado em Jung, "[o devaneio] é verdadeiramente, para todo ser humano, homem ou mulher, um dos estados femininos da alma" (BACHELARD, 2009, p. 20). Se o sonho noturno é animus, o devaneio é anima. O animus está no domínio das preocupações e dos projetos, portanto é futuro; a anima pertence ao presente. O devaneio, ainda segundo Bachelard (2009, p. 70-71),

[...] nos dá o verdadeiro repouso, o repouso feminino. Doçura, lentidão, paz, eis a divisa do devaneio em anima [...] o devaneio sempre nos abre a possibilidade de abstrairmo-nos dos dramas conjugais. Uma das funções do devaneio é libertar-nos dos fados da vida.

No estado de devaneio, há uma idealização tanto do objeto do devaneio quanto do sujeito devaneante, que passa a conhecer uma linguagem sem censura, na medida em que pode dizer tudo a si próprio. Acrescente-se que no devaneio há uma clareza de consciência e que o sujeito da atividade onírica sincretiza-se com o ator do devaneio, uma narração em primeira pessoa, portanto. Por meio dele, o sujeito constrói um mundo tal como sonho. O devaneio é performativo: se eu sonho isso, logo isso existe.

Quanto à categoria espaço, tem-se no conto uma oposição: de um lado, o espaço doméstico, portanto íntimo e privado; de outro lado, o espaço público, social (a tasca, a que fora com marido). O espaço doméstico é, segundo 
Bachelard (2008, p. 36), "um corpo de imagens que dá ao homem razões ou ilusões de estabilidade". A esse espaço corresponde o tempo do devaneio. Ao espaço social, o tempo da embriaguez. O espaço-tempo do devaneio é subjetivo e a ele se associam os desejos, a imaginação. $O$ espaço-tempo da embriaguez é objetivo, e pressupõe-se a exterioridade.

O devaneio se dá num tempo imensurável e imobiliza o sujeito no espaço. Nesse momento de suspensão da temporalidade e da espacialidade, ocorre a fratura e se dá o encontro estésico: "[...] que sensibilidade!, mas que sensibilidade!, quando olhava o quadro tão bem pintado do restaurante ficava logo com sensibilidade artística" (LISPECTOR, 2016b, p. 140). Arrebatada do tempo e do espaço e sensibilizada, a rapariga constrói um novo sentido para sua vida, pela ressemantização do passado e do futuro. Passado esse momento de fratura, de tonificação do afeto, a vida retoma seu curso. Tudo aquilo que crescera e se expandira com o devaneio volta a seu tamanho normal. A intensidade cede lugar à extensidade.

O devaneio da rapariga dilui a separação das categorias tempo e espaço que passam a ser interligadas, configurando o que Bakhtin chama de cronotopo. Segundo o filósofo russo,

No cronotopo artístico-literário ocorre a fusão dos indícios do espaço e do tempo num todo apreendido e concreto. Aqui o tempo se adensa e ganha corporeidade, torna-se artisticamente visível; o espaço intensifica, incorpora-se ao movimento do tempo, do enredo e da história. Os sinais do tempo se revelam no espaço e o espaço é apreendido e mediado pelo tempo (BAKHTIN, 2018, p. 12).

\section{Hipótese de trabalho}

Toma-se por hipótese que o uso da variedade europeia do português no conto dilui a clivagem entre o enunciador e o ator do enunciado. É como se o enunciador deslizasse para o enunciado e se mesclasse com a personagem, instaurando a cumplicidade. A bivocalidade é esmaecida, as vozes se superpõem, as fronteiras entre a voz de um e a de outro deixam de ser nítidas, porque, no 
plano da expressão, as marcas linguísticas que identificam o discurso do ator do enunciado não estão presentes.

Um dos recursos presentes no conto para efetuar essa mescla de vozes, confundindo a voz do narrador-observador com a do ator do enunciado é o discurso indireto livre. Como se sabe, trata-se de uma forma de discurso reportado em que não há subordinação por verbo enunciativo entre o discurso citante e o discurso citado. Duas enunciações se superpõem, o que faz com que se confundam as vozes do narrador-observador com a do ator do enunciado, como se pode observar no trecho do conto que se reproduz a seguir.

Seus olhos de novo fitaram aquela rapariga que, já d'entrada, Ihe fizera subir a mostarda ao nariz. Logo d'entrada percebera-a sentada a uma mesa com seu homem, toda cheia dos chapéus e d'ornatos, loira como um escudo falso, toda santarrona e fina - que rico chapéu que tinha! -, vai ver que nem casada era, e a ostentar aquele ar de santa. E com seu rico chapéu bem-posto. Pois que bem Ihe aproveitasse a beatice!, e que se não the entornasse a fidalguia na sopa! As mais santazitas eram as que mais cheias estavam de patifaria. E o criado de mesa, o grande parvo, a servi-la cheio das atenções, o finório: e o homem amarelo que a acompanhava a fazer vistas grossas. E a santarrona toda vaidosa de seu chapéu, toda modesta de sua cinturita fina, vai ver que não era capaz de parir-lhe, ao seu homem, um filho. Ai que não tinha nada a ver com isso, a bem dizer: mas já d'entrada crescera-lhe a vontade d'ir e d'encher-lhe, à cara de santa loira da rapariga, uns bons sopapos, a fidalguia de chapéu. Que nem roliça era, era chata de peito. vai ver que, com todos os seus chapéus, não passava duma vendeira d'hortaliça a se fazer passar por grande dama (LISPECTOR, 2016b, p. 140).

\section{Atos expressivos}

No conto, podem-se observar, tanto por parte do enunciador quanto por parte da rapariga, expressão de sentimentos súbitos por meio de interjeições, comprovando a hipótese de um deslizamento do narrador heterodiegético da enunciação para o nível do enunciado, com a consequente simbiose enunciador/ator do enunciado. Aliás, tanto um quanto outro se valem da mesma interjeição (al). O levantamento das interjeições do texto mostra que esta é a interjeição dominante, como se pode observar no Quadro 2, abaixo. 
Quadro 2 - Interjeições do narrador e da personagem

\begin{tabular}{|l|l|}
\hline Interjeições do narrador & Interjeições da personagem \\
\hline Ai que esquisita estava... & $A i$, ai, suspirou a rir. \\
\hline Ai que quarto suculento! & $\begin{array}{l}A i, \text { ai, vinha da rua como uma } \\
\text { borboleta. }\end{array}$ \\
\hline Aique não tinha nada a ver com isso, a bem dizer... & Aique não me maces! \\
\hline $\begin{array}{l}\text { Oh, como estava humilhada por ter vindo à tasca sem } \\
\text { chapéu... }\end{array}$ & $\begin{array}{l}\text { Ó mulher, vê lá se me vais mesmo } \\
\text { adoecer! }\end{array}$ \\
\hline $\begin{array}{l}\text { Ai, palavras, palavras, objetos do quarto alinhados em } \\
\text { ordem de palavras... }\end{array}$ & ai que até me faltei ao respeito! \\
\hline Aique malícia. & ai que vagabunda que me saíste! \\
\hline $\begin{array}{l}\text { Ai que se sentia tão bem, tão áspera, como se ainda } \\
\text { estivesse a ter leite nas mamas... }\end{array}$ & Ai que infeliz que sou, minha mãe. \\
\hline Aique tristeza. Que é que se há de fazer. & aique chatura... \\
\hline & $\begin{array}{l}\text { ai de mim, seja lá o que Deus bem } \\
\text { quiser. }\end{array}$ \\
\hline & $\begin{array}{l}\text { Ai, é uma tal coisa que se me dá que } \\
\text { nem bem sei dizer. }\end{array}$ \\
\hline & Aique cousa que se me dá \\
\hline & $\begin{array}{l}\text { ai que cousa que se me dá, minha } \\
\text { santa mãe! }\end{array}$ \\
\hline
\end{tabular}

Fonte: Elaboração própria

Nos enunciados, a interjeição ai não tem, como em ó, heim?, olá! psiu!, valor interativo, mas valor sintomático expressando estado emocional sem implicar participação do enunciatário. O logos, discurso do narrador, se deixa contaminar pelo pathos da personagem.

A interjeição encaixa-se no que se pode denominar de ato expressivo, na medida em que expressa um sentimento do enunciador. Atendo-se ao seu sentido etimológico, interjectio, onis, trata-se de palavra assintática ${ }^{3}$ que se "interjecta" no discurso para trazer a ele estados de alma vivos e súbitos. Seu aspecto é pontual.

O fato de, em Devaneio e embriaguez duma rapariga, as falas da rapariga estarem marcadas por atos expressivos não causa qualquer estranheza, na

3 Maria Helena de Moura Neves (2018, p. 1124), em sua A gramática do português revelada em textos, deixa claro o caráter assintático da interjeição ao afirmar que esse tipo de palavra "é, de fato, uma peça avulsa na frase. Tal como o vocativo, ela não é propriamente um termo da oração, não pertencendo nem ao predicado nem ao sujeito". Carone, apoiada em Tesnière, sustenta que interjeições "não são um tipo de vocábulo, embora a gramática oficial se aferre à tradição e as considere uma décima classe de palavras. Não são vocábulos porque, não se constituindo de morfemas, desconhecem a articulação mórfica (primeira articulação); apresentam apenas a articulação fonológica (segunda articulação) e, por vezes, até configurações fonemáticas insólitas na língua" (CARONE, 1999, p. 47). 
medida em que as interjeições fazem parte de atos enunciativos em discurso direto, como se observa no trecho a seguir: "Ai, é uma tal coisa que se me dá que nem bem sei dizer". A interjeição expressa o assomo, uma vivência de significação. Zilberberg (2011, p. 21) afirma que a interjeição funciona como uma espécie de não-resposta a um assomo exclamativo brutal, expressando "a transição entre o mutismo daquele a quem o acontecimento deixou 'sem voz', como se costuma dizer, e a retomada da palavra".

Quanto ao narrador, sua voz é expressa em terceira pessoa, o que, em princípio, deveria conferir um efeito de sentido de objetividade. Não é isso o que ocorre. A voz do narrador, embora heterodiegético, está plena de interjeições, que atestam a empatia pelo ator do enunciado.

As interjeições do narrador, mais do que exprimir uma emoção, exprimem a compaixão deste pelo infortúnio da personagem. Compaixão aqui entendida em seu sentido etimológico, compassio, onis, ou seja, sentir junto, sofrer junto.

\section{Considerações Finais}

Em Devaneio e embriaguez duma rapariga, de Clarice Lispector, tem-se um conto original na produção literária brasileira, já que é o único conto que se conhece em que o (a) autor (a), embora falante nativo da variedade brasileira do português, constrói um enunciador falante da variedade europeia. O que, numa primeira leitura, poderia parecer apenas um experimento lúdico, um jogo verbal por parte da autora, revela, numa análise mais profunda, que a escolha da variedade europeia, aliada a outros procedimentos discursivos, como as interjeições do narrador-observador e figuras que remetem ao contexto português, embora a ação se passe no Rio de Janeiro, na verdade é uma opção discursiva que possibilita ao enunciador deslizar para o enunciado, identificandose e solidarizando-se com o ator do enunciado. Se há no conto disjunções espácio-temporais: tempo-espaço do devaneio, tempo-espaço da embriaguez; oposições de valores: liberdade vs. dominação; família vs. indivíduo, obrigações domésticas vs. realização pessoal, tudo é esmaecido. Os conflitos são resolvidos 
porque a clivagem ator da enunciação vs. ator do enunciado é apagada pela narrativa em favor de uma conjunção de sentimentos, porque esses actantes se configuram num só e o que permite a simbiose é simplesmente o discurso, porque embora feito de vozes diferentes, elas se mesclam numa única voz, a da compaixão.

\section{Referências}

BACHELARD, Gaston. $A$ poética do devaneio. 3. ed. Tradução de Antônio de Pádua Danesi. São Paulo: Editora WMF, 2009.

BACHELARD, Gaston. A poética do espaço. 2. ed. Tradução de Antônio da Costa Leal e Lídia do Valle Santos Leal. São Paulo: Martins Fontes, 2008.

BAKHTIN, Mikhail. Teoria do romance II: As formas do tempo e do cronotopo. Tradução de Paulo Bezerra. São Paulo: Editora 34, 2018.

CARONE, Flávia de Barros. Morfossintaxe. 8. ed. São Paulo: Ática, 1999.

LISPECTOR, Clarice. Apêndice: a explicação inútil. In: LISPECTOR, Clarice. Todos os contos. Organização de Benjamin Moser. Rio de Janeiro: Editora Rocco, 2016a. p. 643-644.

LISPECTOR, Clarice. Devaneio e embriaguez duma rapariga. In: LISPECTOR, Clarice. Todos os contos. Organização de Benjamin Moser. Rio de Janeiro: Editora Rocco, 2016b. p. 135-144.

MIRA MATEUS, Maria Helena; BRITO, Ana Maria; DUARTE, Inês, HUB FARIA Isabel. Gramática da língua portuguesa. 2. ed. Lisboa: Editorial Caminho, 1989. (Coleção Universitária. Série Linguística).

NEVES, Maria Helena de. A gramática do português revelada em textos. São Paulo: Editora UNESP, 2018.

ORLANDI, Eni Pucinelli. Língua e conhecimento linguístico: para uma história das ideias no Brasil. São Paulo: Editora Cortez, 2002.

ZILBERBERG, Claude. Elementos de semiótica tensiva. Tradução de Ivã Carlos Lopes, Luiz Tatit e Waldir Beividas. São Paulo: Ateliê Editorial, 2011. 